\title{
ANALISIS PERBANDINGAN ANGGARAN BIAYA PEKERJAAN BETON EXISTING K250 DAN ALTERNATIF K300 BERDASARKAN REKAYASA NILAI
}

\author{
Ni Kadek Sri Ebtha Yuni' ${ }^{1)}$, Putu Eny Suhardiyani2), dan I Putu Widyarsana ${ }^{2)}$ \\ 1) Jurusan Teknik Sipil, Politeknik Negeri Bali, Badung, Bali \\ 2) Jurusan Sistem Informasi, ITB Stikom Bali, Denpasar, Bali \\ ebthayuni@pnb.ac.id
}

\begin{abstract}
Project cost control is important in the project management process to avoid losses. Project control can be carried out in terms of cost and time. One way to control project costs is to choose the design, materials to be used in the project, and the implementation methods to be used. The objective of this study is to obtain an alternative structural design with an optimal construction cost of structural work by considering the use of concrete quality in reinforced concrete structures, column spacing and cross-sectional dimensions of structural elements. The existing design is to use quality K250 concrete. In this study the cost analysis of the concrete structure, foundation, tie beam, beam, column and ring beam work results from value engineering. The stages of research start from the design information stage, the creative stage that is determining the design alternatives and the analysis stage. The analysis was carried out by structural analysis using SAP2000 and analysis of concrete work costs. The results of the analysis of alternative designs namely reducing the dimensions of the cross-section, using K300 quality concrete, eliminating structural elements that do not need to meet in the calculation of the structure. The next step is to calculate the cost of the concrete work. Concrete structure work when using an alternative design that is to reduce the dimensions of the structure, change the quality to K300 and eliminate unnecessary elements that can save costs by IDR.35,956,756.00 or $37.02 \%$.
\end{abstract}

Keywords: concrete work, alternative designs, value engineering 


\begin{abstract}
ABSTRAK
Pengendalian biaya proyek merupakan hal yang penting dalam proses pengelolaan proyek untuk menghindari kerugian. Pengendalian proyek dapat dilakukan dalam aspek biaya dan waktu. Salah satu cara untuk melakukan pengendalian biaya proyek adalah pemilihan desain, bahan atau material yang akan digunakan dalam proyek, dan metode pelaksanaan yang akan digunakan. Penelitian ini bertujuan untuk mendapatkan alternatif desain struktur dengan biaya konstruksi pekerjaan struktur yang optimal dengan mempertimbangkan penggunaan mutu beton pada struktur beton bertulang, jarak kolom dan dimensi penampang elemen struktur. Desain eksisting adalah menggunakan mutu beton K250. Pada penelitian ini dilakukan analisis biaya pekerjaan beton struktur pondasi, sloof, balok, kolom dan ring balok hasil dari rekayasa nilai. Tahapan penelitian dimulai dari tahap informasi desain, tahap kreatif yaitu menentukan alternatif desain dan tahap analisis. Analisis dilakukan dengan analisis struktur menggunakan SAP2000 dan analisis biaya pekerjaan beton. Hasil analisis desain alternatif yaitu memperkecil dimensi penampang, menggunakan beton mutu K300, menghilangkan elemen struktur yang tidak perlu memenuhi dalam perhitungan stuktur. Tahap selanjutnya adalah menghitung biaya pekerjaan beton. Pekerjaan beton struktur apabila menggunakan desain alternatif yaitu memperkecil dimensi penampang struktur, mengganti mutu menjadi K300 dan menghilangkan elemen yang tidak perlu dapat menghemat biaya sebesar Rp.35,956,756.00 atau $37.02 \%$.
\end{abstract}

Kata kunci: pekerjaan beton, desain alternatif, rekayasa nilai 


\section{PENDAHULUAN}

Pengendalian biaya proyek merupakan hal yang penting dalam proses pengelolaan proyek. Pemilihan desain, bahan atau material yang akan digunakan dalam proyek, dan metode pelaksanaan yang akan digunakan memberikan pengaruh terhadap besarnya biaya proyek tersebut serta akan berpengaruh dalam mendapatkan hasil konstruksi yang efektif dan efisien. Salah satu solusi yang dapat digunakan untuk menekan biaya dalam pelaksanaan suatu proyek adalah dengan melakukan rekayasa nilai atau yang sering disebut value engineering. Value engineering dilakukan dengan menghilangkan biaya-biaya yang tidak diperlukan tanpa mengurangi fungsi, penampilan, kualitas dan keandalan proyek (Miles, 1972).

Berdasarkan penelitian Andilistiono (2011), bahwa desain struktur beton yang menggunakan mutu K225 diganti dengan mutu K275 memperoleh penghematan biaya pekerjaan plat sebesar $\mathrm{Rp}$ 112.962.485 dan penghematan pekerjaan balok sebesar Rp 8.552.580. Pada proyek pembangunan Gedung Pendidikan Politeknik Elektronika Negeri Surabaya, diperoleh 3 item pekerjaan yang bisa dilakukan analisis value engineering, dan hasilnya adalah penghematan biaya $0.25 \%$ untuk pekerjaan pelapis dinding luar, $0.395 \%$ untuk pekerjaan dinding, dan $0.79 \%$ untuk pekerjaan pelapis lantai (Ayudya, 2012)

Pada proyek pembangunan salah satu gedung SD Negeri di Kabupaten Badung, dengan luas bangunan $234 \mathrm{~m} 2$ dan nilai kontrak $\mathrm{Rp}$ 1.896.000.000, pekerjaan struktur beton bertulang menggunakan beton dengan mutu K250. Penggunaan mutu beton K250 pada proyek tersebut menghasilkan desain konstruksi dengan jumlah elemen struktur yang banyak, ukuran dimensi penampang besar, dan volume beton yang besar. Berdasarkan pertimbangan penulis, desain struktur yang ada dengan mutu beton dan jarak bentang struktur yang dekat satu dengan lainnya dapat dilakukan review atau peninjauan kembali serta ada alternatif lain yang menghasilkan biaya pelaksanaan lebih rendah.

Berdasarkan latar belakang di atas penulis melakukan penelitian untuk melakukan rekayasa nilai dengan menggantikan mutu beton K250 menjadi K300.

\section{KAJIAN PUSTAKA}

\subsection{Value Engineering/Rekayasa Nilai} Value engineering dapat didefinisikan sebagai suatu sistem 
pemecahan masalah yang dilaksanakan dengan menggunakan teknik tertentu yang memiliki tujuan untuk mendefinisikan dan menghilangkan biaya-biaya yang tidak diperlukan (Miles, 1972).

\subsection{Tahapan Analisis Value Engineering/ Rekayasa Nilai}

Adapun tahapan-tahapan dalam value engineering dengan menggunakan Four Phase Job Plan (Dell'Isola, 1972), antara lain:

1. Tahap Informasi adalah tahap awal dalam rencana kerja value engineering. Dalam tahap ini, dilakukan pengumpulan informasi dan data-data yang dibutuhkan dalam proses analisis.

2. Tahap Kreatif adalah ide-ide kreatif mengenai alternatifalternatif yang digunakan dikeluarkan, dikumpulkan dan dianalisis dengan penuh pertimbangan.

3. Tahap Analisis yaitu dilakukannya evaluasi terhadap alternatif yang dipilih, dari eveluasi tersebut akan menghasilkan informasi berupa kelayakan alternatif.

4. Tahap Pengembangan dan Rekomendasi Tahap ini merupakan tahap akhir dalam rencana kerja value engineering yang bertujuan menawarkan atau memberikan laporan mengenai seluruh tahap kepada pihak manajemen atau pemberi tugas untuk mendapatkan keputusan apakah alternatif yang dipilih dapat digunakan dan dilakukan dengan baik. Rekomendasi ini nantinya digunakan untuk meyakinkan pemilik proyek untuk mengambil keputusan.

\subsection{Struktur Bangunan}

Struktur dalam konteks hubungannya dengan bangunan dapat didefinisikan sebagai sarana memikul dan menyalurkan beban dari bangunan hingga ke tanah. Dalam perencanaan suatu bangunan, struktur bangunan merupakan elemen terpenting yang perencanaannya harus matang. Hal seperti jenis material, sistem pembebanan dan gaya-gaya yang bekerja pada bangunan diperhatikan dalam perencanaan struktur suatu bangunan sehingga suatu bangunan dapat berdiri kokoh tanpa ada kerusakan yang berarti akibat kesalahan perencanaan (Hartono, 1999). 
Elemen-elemen struktur suatu bangunan adalah pondasi, kolom, balok, plat lantai.

\subsection{SAP 2000}

SAP adalah singkatan dari Structural Analysis Programs (Program Analisis Struktur) atau dalam istilah lama disebut Program Mekanika Teknik, yaitu suatu analisis gaya-gaya yang bekerja dalam struktur untuk bidang teknik (Faqih, 2008).

Beban-beban yang digunakan dalam menjalankan program ini mengacu pada Peraturan SNI 02-1727-2013 tentang Beban Minimum Untuk Perancangan Bangunan Gedung dan Struktur Lain. Analisis struktur dengan menggunakan SAP2000 memerlukan ilmu dan keahlian khusus serta konsep yang memadai agar dihasilkan analisis yang akurat. Berikut merupakan langkah-langkah analisis struktur menggunakan Program SAP2000:

1. Menjalankan program SAP2000 dengan klik 2 (dua) kali pada icon program SAP2000.

2. Mengatur satuan yang digunakan pada kolom satuan di pojok kanan bawah layar.

3. Memulai lembar kerja baru dengan klik menu file - new model.
4. Memilih template untuk permodelan struktur.

5. Memasukkan jenis dan propertis material yang digunakan dalam analisis (Define Materials) dengan cara klik Menu Define Materials - Add New Material.

6. Menetapkan bentuk penampang struktur bangunan beserta material yang digunakan (Define Frame Section) dengan cara klik Menu Define - Section Properties - Frame Sections.

7. Memasukkan jenis - jenis beban yang terjadi pada struktur bangunan (Define Load Patterns) dengan cara klik Menu Define - Load Patterns.

8. Memasukkan jenis - jenis kombinasi beban yang terjadi sesuai dengan peraturan (Define Load Combinations) dengan cara klik Menu Define - Load Combinations.

9. Memodelisasi rangka struktur dan menetapkan (assign) frame yang digunakan.

10. Menetapkan pengaturan analisis dengan cara klik Menu Analyze - Set Analysis Options.

11. Menetapkan beban yang akan dianalisis dengan cara klik Menu 
Analyze - Set Load Cases To Run.

12. Memulai proses analisis gaya gaya dalam struktur dengan cara klik Menu Analyze - Run Analysis.

13. Memulai proses analisis struktur baja agar dapat diketahui penampang yang mengalami kelebihan beban dengan cara klik Menu Design - Steel Frame Design - Select Design Combos untuk memilih kombinasi beban yang digunakan dalam perencanaan.

14. Memulai proses design struktur baja dengan cara klik Menu Design - Steel Frame Design View/Revise Preferences.

\subsection{Perencanaan Anggaran Biaya}

Perencanaan biaya suatu bangunan atau proyek ialah perhitungan biaya yang diperlukan untuk bahan dan upah, serta biaya-biaya yang berhubungan dengan pelaksanaan bangunan dan proyek tersebut. Kegiatan perencanaan dilakukan dengan terlebih dahulu mempelajari gambar rencana dan spesifikasi. Bedasarkan gambar rencana, dapat diketahui kebutuhan material yang nantinya akan digunakan. Perhitungan dapat dilakukan secara teliti dan kemudian ditentukan harganya. Dalam melakukan kegiatan perencanaan, seseorang perencana harus memahami proses konstruksi secara menyeluruh, termasuk jenis dan kebutuhan alat karena faktor tersebut dapat mempengaruhi biaya konstruksi (Novel Lantang, 2014).

Tahap dalam menyusun anggaran biaya adalah menghitung volume pekerjaan dan menyusun analisa harga satuan pekerjaan. Anggaran biaya pada bangunan yang sama akan berbeda-beda dimasing-masing daerah, disebabkan karena perbedaan harga bahan dan upah tenaga kerja (Novel Lantang, 2014).

Peraturan Menteri Pekerjaan Umum dan Perumahan Rakyat Nomor: 28/Prt/M/2016 tentang Pedoman Analisis Harga Satuan Pekerjaan Bidang Pekerjaan Umum, pasal 1 ayat 1 menyatakan Analisis Harga Satuan Pekerjaan yang selanjutnya disingkat AHSP adalah perhitungan kebutuhan biaya tenaga kerja, bahan dan peralatan untuk mendapatkan harga satuan atau satu jenis pekerjaan tertentu.

\section{METODE PENELITIAN}

\subsection{Rancangan Penelitian}

Pelaksanaan penelitian dilakukan deskriptif kuantitatif dengan metode penelitian menggunakan analisa value engineering/ rekayasa nilai pada 
komponen beton pondasi, sloof, kolom, balok, dan ring balok.

\subsection{Penentuan Sumber Data}

Data diperoleh melalui pengumpulan data primer dan sekunder. Data sekunder yang digunakan pada penelitian ini adalah gambar rencana, rencana anggaran biaya (RAB), analisa harga satuan pekerjaan (AHSP), pekerjaan struktur, dan SNI yang berhubungan dengan tinjauan penelitian ini. Data primer berupa alternatif desain, dan rencana anggaran biaya (RAB) alternatif.

\subsection{Analisis Data}

Analisis data yang dilakukan sesuai dengan tahapan-tahapan pada analisis value engineering. Adapun tahapantahapannya adalah:

1. Tahap Informasi: yaitu informasi umum proyek tersebut seperti nama proyek, lokasi proyek, pemilik proyek, fungsi gedung, luas area proyek, biaya proyek, dan waktu pelaksanaan.

2. Tahap kreatif: adapun acuan untuk membantu menentukan alternatif kreatif yaitu material, dimensi disain, sumber daya proyek, peralatan.

3. Tahap analisis yaitu menggunakan potensi biaya yang optimal. Tahap untuk menganalisis struktur dengan program SAP 2000, dilanjutkan analisis biaya dengan menghitung volume pekerjaan. Analisa harga satuan yang digunakan adalah berdasarkan analisa harga satuan kontrak.

4. Tahap rekomendasi memberikan rekomendasi dari alternatif yang dipilih untuk diajukan kepada pihak-pihak tertentu.

\section{HASIL DAN PEMBAHASAN}

Analisis value engineering dilakukan pada pekerjaan beton yang meliputi pekerjaan pondasi, pekerjaan sloof, pekerjaan kolom, pekerjaan balok dan pekerjaan ring balok.

\subsection{Tahap Informasi}

Informasi umum desain merupakan informasi penting yang harus diketahui oleh peneliti dalam melakukan analisis. Informasi umum desain menjadi acuan analisa value engineering. Informasi umum desain tersebut antara lain: 
Tabel 1. Tabel Desain Existing

\begin{tabular}{clccc}
\hline No & \multicolumn{1}{c}{ Uraian } & $\begin{array}{c}\text { Dimensi } \\
(\mathrm{cm})\end{array}$ & Tulangan & $\begin{array}{c}\text { Mutu } \\
\text { beton }\end{array}$ \\
\hline 1 & Pondasi (P1) & $75 \times 75$ & D19, D16 & K250 \\
2 & Sloof & & & \\
& S1 & $20 \times 35$ & D16, $\phi 8$ & K250 \\
& S2 & $15 \times 20$ & D16, $\phi 8$ & K250 \\
3 & Kolom & & & \\
& K1 & $35 \times 35$ & D16, $\phi 8$ & K250 \\
& K2 & $30 \times 30$ & D16, $\phi 8$ & K250 \\
& K3 & $20 \times 20$ & D16, $\phi 8$ & K250 \\
4 & Balok & & & \\
& B1 & $35 \times 60$ & D16, $\phi 8$ & K250 \\
& B2 & $25 \times 35$ & D16, $\phi 8$ & K250 \\
& B3 & $20 \times 30$ & D16, $\phi 8$ & K250 \\
5 & Ring Balok & $20 \times 30$ & D16, $\phi 8$ & K250 \\
\hline
\end{tabular}

Kondisi exsisting proyek adalah dengan spesifikasi beton menggunakan K250, dimensi berbeda-beda dan tulangan D16, $\phi 8$. Dengan menggunakan desain existing, maka rincian biaya pekerjaan beton adalah sebagai berikut:

\section{Tabel 2. Rincian Biaya Pekerjaan Beton dengan Mutu K250}

\begin{tabular}{clc}
\hline No & \multicolumn{1}{c}{ Uraian } & $\begin{array}{c}\text { Jumlah Harga } \\
(\mathrm{Rp})\end{array}$ \\
\hline 1 & $\begin{array}{l}\text { Pekerjaan beton } \\
\text { pondasi }\end{array}$ & $12,191,548$ \\
2 & $\begin{array}{l}\text { Pekerjaan beton } \\
\text { sloof }\end{array}$ & $15,458,676$ \\
3 & $\begin{array}{l}\text { Pekerjaan beton } \\
\text { kolom }\end{array}$ & $34,167,286$ \\
4 & $\begin{array}{l}\text { Pekerjaan beton } \\
\text { balok }\end{array}$ & $26,910,821$ \\
5 & $\begin{array}{l}\text { Pekerjaan beton } \\
\text { ring balok }\end{array}$ & $8,399,959$ \\
\hline & Total & $\mathbf{9 7 , 1 2 8 , 2 9 0}$ \\
\hline
\end{tabular}

Dari tabel di atas, pekerjaan beton dengan desain existing menghabiskan biaya sebesar Rp.97,128,290.00.

\subsection{Tahap Kreatif}

Adapun tahap kreatif yang yang dimaksud adalah seperti tabel 3 berikut:

Tabel 3. Desain Alternatif

\begin{tabular}{llccc}
\hline No & \multicolumn{1}{c}{ Uraian } & $\begin{array}{c}\text { Dimensi } \\
(\mathrm{cm})\end{array}$ & Tulangan & $\begin{array}{c}\text { Mutu } \\
\text { beton }\end{array}$ \\
\hline 1 & Pondasi (P1) & $100 \times 100$ & D19, D16 & K300 \\
2 & Sloof & & & \\
& S1 & $20 \times 35$ & D16, $\phi 8$ & K300 \\
& S2 & $15 \times 20$ & D16, $\phi 8$ & K300 \\
3 & Kolom & & & \\
& K1 & $30 \times 30$ & D16, $\phi 8$ & K300 \\
& K2 & $25 \times 25$ & D16, $\phi 8$ & K300 \\
4 & Balok & & & \\
& B1 & $30 \times 40$ & D16, $\phi 8$ & K300 \\
& B2 & $20 \times 30$ & D16, 88 & K300 \\
& B3 & $15 \times 25$ & D16, 88 & K300 \\
5 & Ring Balok & $15 \times 25$ & D16, 88 & K300 \\
\hline
\end{tabular}

Pertimbangan penulis memilih alternatif yang digunakan yaitu dari komposisi bahan campuran beton existing dengan alternatif terpilih. Komposisi bahan campuran beton yang dimaksud sebagai berikut:

Tabel 4. Komposisi Bahan Campuran Beton Untuk 1 m $^{3}$ Beton

\begin{tabular}{ccccc}
\hline \multirow{2}{*}{ No } & \multirow{2}{*}{ Alternatif } & \multicolumn{3}{c}{ Kebutuhan $(\mathrm{kg})$} \\
\cline { 3 - 5 } & & Semen & Pasir & Koral \\
\hline 1 & $\begin{array}{c}\text { K250 } \\
\text { (existing) }\end{array}$ & 384 & 692 & 1.039 \\
2 & K300 (alt) & 413 & 681 & 1.021 \\
\hline
\end{tabular}

Komposisi bahan campuran beton menjadi suatu pertimbangan dipilihnya alternatif tersebut, kelebihan dan kekurangan dari alternatif itu sendiri juga menjadi pertimbangannya. 


\subsection{Tahap Analisis}

Tahap analisis adalah tahap lanjutan terhadap alternatif yang telah dipilih pada tahap kreatif, dimana dilakukan analisis dan pengevaluasian terhadap alternatif. Adapun tahapan-tahapan dalam melakukan analisis terhadap alternatif terpilih tersebut yaitu analisis perencanaan struktur, dan analisis anggaran biaya.

\subsubsection{Analisis Perencanaan Struktur}

Perencanaan struktur pada penelitian ini menggunakan Program Aplikasi SAP2000 dalam mencari gaya-gaya dalam dan dimensi elemen struktur yang digunakan. Hasil analisis penampang alternatif adalah sebagai berikut:

Tabel 5. Tulangan Sloof

\begin{tabular}{ccccc}
\hline & $\begin{array}{c}\text { Output } \\
\text { TyP200 } \\
\text { Ftop } \\
\left(\mathrm{m}^{2}\right)\end{array}$ & $\begin{array}{c}\text { Output } \\
\text { SAP200 } \\
\text { Fbot }\left(\mathrm{m}^{2}\right)\end{array}$ & $\begin{array}{c}\text { Jumlah } \\
\text { Tul } \\
\text { Bawah } \\
(\mathrm{bh})\end{array}$ & $\begin{array}{c}\text { Jumlah } \\
\text { Tul } \\
\text { Bawah } \\
(\mathrm{bh})\end{array}$ \\
\hline S1 & 0.000459 & 0.000397 & 3 & 2 \\
S2 & 0.000319 & 0.000252 & 2 & 2 \\
\multicolumn{2}{c}{ Sengkang } & Tumpuan & Lap. & \\
& & 100 & 150 & \\
\hline
\end{tabular}

Berdasarkan data hasil perhitungan, dimensi sloof alternatif S1 menggunakan tulangan 5D16 dengan jarak sengkang tumpuan $100 \mathrm{~mm}$ dan lapangan $150 \mathrm{~mm}$. S2 menggunakan tulangan 4D16 dengan jarak sengkang tumpuan $100 \mathrm{~mm}$ dan lapangan $150 \mathrm{~mm}$.
Berdasarkan hasil analisis SAP2000 diperoleh tulangan kolom sebagai berikut:

Tabel 6. Tulangan Kolom

\begin{tabular}{ccccc}
\hline Type & $\begin{array}{c}\text { Output } \\
\text { SAP 2000 } \\
\left(\mathrm{m}^{2}\right)\end{array}$ & $\begin{array}{c}\text { Jumlah } \\
\text { Tul. } \\
(\text { bh) }\end{array}$ & $\begin{array}{c}\text { Jarak } \\
\text { sengkang } \\
\text { tup.(mm) }\end{array}$ & $\begin{array}{c}\text { Jarak } \\
\text { sengkang } \\
\text { lap. (mm) }\end{array}$ \\
\hline K1 & 0.001019 & 8 & 100 & 150 \\
K2 & 0.000442 & 6 & 100 & 150 \\
\hline
\end{tabular}

Desain alternatif kolom K1 menggunakan tulangan 8D16 dengan jarak sengkang tumpuan $100 \mathrm{~mm}$ dan lapangan $150 \mathrm{~mm}$. K2 menggunakan tulangan 6D16 dengan jarak sengkang tumpuan $100 \mathrm{~mm}$ dan lapangan $150 \mathrm{~mm}$.

\subsubsection{Analisis Anggaran Biaya}

Analisis anggaran biaya diperhitungkan berdasarkan desain alternatif yang sudah masuk dalam perhitungan struktur menggunakan SAP2000.

1. Menghitung Volume Pekerjaan Adapun perbandingan volume pekerjaan desain existing dengan alternatif dapat dilihat pada Tabel 7 . Dari Tabel 7, volume beton desain alternatif lebih sedikit daripada desain existing. Hal ini diakibatkan oleh perubahan dimensi penampang yang lebih kecil dan menghilangkan beberapa elemen struktur yang tidak perlu. 
Tabel 7. Perbandingan volume beton desain existing dan alternatif

\begin{tabular}{clcc}
\hline No & \multicolumn{1}{c}{ Uraian } & $\begin{array}{c}\text { Existing } \\
\left(\mathrm{m}^{3}\right)\end{array}$ & $\begin{array}{c}\text { Alternatif } \\
\left(\mathrm{m}^{3}\right)\end{array}$ \\
\hline 1 & Pondasi (P1) & 14.18 & 8.7 \\
2 & Sloof & & \\
& S1 & 17.73 & 10.56 \\
& S2 & 0.25 & 0.25 \\
3 & Kolom & & \\
& K1 & 29.92 & 20.00 \\
& K2 & 9.82 & 5.25 \\
4 & Balok & & \\
& B1 & 25.98 & 16.27 \\
& B2 & 5.07 & 2.71 \\
& B3 & 0.25 & 0.15 \\
5 & Ring Balok & 9.77 & 5.00 \\
\hline
\end{tabular}

2. Analisa Harga Satuan Pekerjaan Beton

Analisa harga satuan untuk desain alternatif beton dengan mutu K300 menggunakan harga satuan kontrak yang mengacu pada Peraturan Menteri Pekerjaan Umum dan Perumahan Rakyat Nomor: 28/Prt/M/2016.

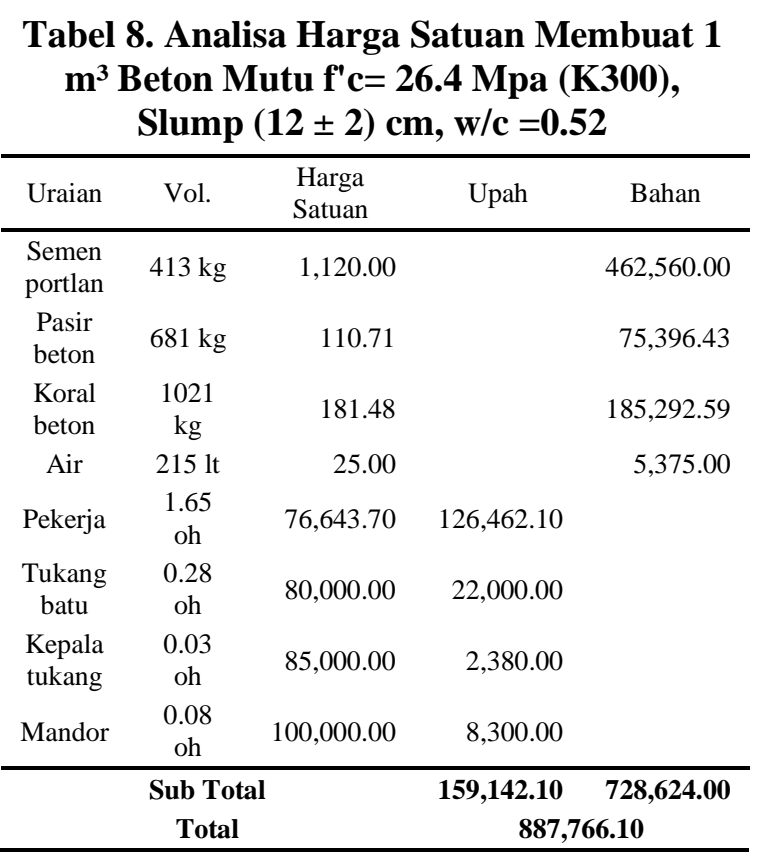

Berdasarkan Tabel 8 analisa harga satuan pekerjaan beton mutu K300 adalah Rp.887,766.10.

\section{Biaya Alternatif}

Biaya alternatif adalah perkalian antara volume pekerjaan dengan analisa harga satuan.

Tabel 9. Biaya Alternatif Pekerjaan Beton

\begin{tabular}{clccr}
\hline No & Uraian & $\begin{array}{r}\text { Vol. } \\
\left(\mathrm{m}^{3}\right)\end{array}$ & $\begin{array}{c}\text { Harga } \\
\text { Satuan } \\
(\mathrm{Rp})\end{array}$ & \multicolumn{1}{c}{ Total (Rp) } \\
\hline 1 & $\begin{array}{l}\text { Pondasi } \\
\text { (P1) }\end{array}$ & 8.7 & $887,766.10$ & $7,723,565.30$ \\
2 & Sloof & & & \\
& S1 & 10.56 & $887,766.10$ & $9,374,810.29$ \\
& S2 & 0.25 & $887,766.10$ & $223,717.06$ \\
3 & Kolom & & & \\
& K1 & 20.00 & $887,766.10$ & $17,755,322.52$ \\
& K2 & 5.25 & $887,766.10$ & $4,660,772.16$ \\
4 & Balok & & & \\
& B1 & 16.27 & $887,766.10$ & $14,445,730.40$ \\
& B2 & 2.71 & $887,766.10$ & $2,412,948.33$ \\
& B3 & 0.15 & $887,766.10$ & $135,828.22$ \\
5 & Ring & 5.00 & $887,766.10$ & $4,438,830.63$ \\
\hline & Balok & & & $\mathbf{6 1 , 1 7 1 , 5 2 5 . 0 0}$ \\
\hline
\end{tabular}

Berdasarkan hasil dari perkalian antara volume pekerjaan dengan analisa harga satuan diperoleh total pekerjaan beton dengan menggunakan mutu K300 sesuai desain alternatif adalah Rp.61,171,525.00.

4. Perbandingan Biaya
Adapun perbandingan biaya pekerjaan beton dengan kondisi existing dan alternatif adalah sebagai berikut: 
Tabel 10. Perbandingan Biaya Pekerjaan Beton

\begin{tabular}{ccrr}
\hline No & Uraian & Existing $(\mathrm{Rp})$ & Alternatif $(\mathrm{Rp})$ \\
\hline 1 & $\begin{array}{l}\text { Pekerjaan } \\
\text { beton } \\
\text { pondasi }\end{array}$ & $12,191,547.82$ & $7,723,565.30$ \\
2 & $\begin{array}{l}\text { Pekerjaan } \\
\text { beton sloof } \\
\end{array}$ & $15,458,676.00$ & $9,598,527.00$ \\
3 & $\begin{array}{l}\text { Pekerjaan } \\
\text { beton kolom }\end{array}$ & $34,167,286.00$ & $22,416,095.00$ \\
$4 \quad \begin{array}{l}\text { Pekerjaan } \\
\text { beton balok }\end{array}$ & $26,910,821.00$ & $16,994,507.00$ \\
& $\begin{array}{l}\text { Pekerjaan } \\
\text { beton ring } \\
\text { balok }\end{array}$ & $8,399,959.00$ & $4,438,830.63 .0$ \\
& $\mathbf{9 7 , 1 2 8 , 2 9 0 . 0 0}$ & $\mathbf{6 1 , 1 7 1 , 5 2 5 . 0 0}$ \\
\hline $\begin{array}{l}\text { Total } \\
\text { Penghematan } \\
\text { biaya }\end{array}$ & $\mathbf{3 5 , 9 5 6 , 7 6 5 . 0 0}$ & $\mathbf{3 7 . 0 2 \%}$ \\
\hline
\end{tabular}

Biaya pekerjaan beton struktur dengan menggunakan desain existing dan alternatif Rp.97,128,290.00 dan Rp.61,171,525.00. Terdapat penghematan biaya sebesar Rp.35,956,756.00 atau $37.02 \%$ apabila menggunakan desain alternatif.

\section{SIMPULAN DAN SARAN}

\subsection{Simpulan}

Pekerjaan beton pada struktur pondasi, sloof, kolom, balok dan ring balok yang kondisi existing menggunakan mutu K250 diganti dengan alternatif beton mutu K300 dapat menghemat biaya sebesar Rp.35,956,756.00 atau 37.02\%

\subsection{Saran}

Perlu dilakukan analisis lebih lanjut terhadap biaya pembesian dan bekisting, dan durasi pelaksanaan pekerjaan.

\section{DAFTAR PUSTAKA}

Andilistiono. (2011). Aplikasi Value Engineering terhadap Struktur Plat dan Balok pada Proyek Pembangunan Gedung Asrama Putra SMP MTA Gemolong. Perpustakaan UNS.

Ayudya.S.P. (2012). Penerapan Rekayasa Nilai pada Proyek Pembangunan Gedung Pendidikan Politeknik Elektronika Negeri Surabaya. Perpustakaan ITS.

Badan Standardisasi Nasional. (2013). SNI 02-1727-2013 tentang Beban Minimum Untuk Perancangan Bangunan Gedung dan Struktur Lain. Jakarta.

Dell'Isola, A. (1972). Value Engineering in the Construction Industry. New York: Construction Publishing Corp., Inc.

Faqih, N. (2008). Analisis Desain Konstruksi dengan Perhitungan Manual dan Program SAP 2000 Versi 9 (Studi Kasus Konstruksi Portal Dengan Permodelan 3 Dimensi). Fakultas Teknik UNSIQ Wonosobo.

Hartono, J. (1999). Analisis dan Disain Sistem Informasi: Pendekatan Terstrutur Teori dan Praktek Aplikasi Bisnis Edisi 2. Andi: Yogyakarta.

Lantang, F.N. (2014). Perencanaan Biaya dengan Menggunakan Perhitungan Biaya Nyata pada Proyek Perumahan (Studi Kasus Perumahan Green Hill Residence). Jurnal Sipil Statik, 2(2).

Miles, L. (1972). Techniques of Value Analysis and Engineering. New York: Mc. Graw-H. 
Pemerintah Indonesia. (2016). Peraturan Menteri Pekerjaan Umum dan Perumahan Rakyat Republik Indonesia Nomor 28/PRT/M/2016 tentang Pedoman Analisis Harga Satuan Pekerjaan Bidang Pekerjaan Umum. Jakarta: Sekreteriat Negara. 